\title{
The Role of Renewable Energy in China's Sustainable Energy Transition
}

\author{
Xiao-yang SUN* \\ School of Business Administration \\ China University of Petroleum, Beijing \\ Beijing, China \\ sunxiaoyangsunfeng@126.com \\ Liang-ping ZOU \\ School of Business Administration \\ China University of Petroleum, Beijing \\ Beijing, China \\ 479123736@qq.com
}

\author{
Bao-sheng ZHANG \\ School of Business Administration \\ China University of Petroleum, Beijing \\ Beijing, China \\ zbs9211@sina.com \\ Rui-zhi WANG \\ School of Business Administration \\ China University of Petroleum, Beijing \\ Beijing, China \\ gadnessy@163.com
}

\begin{abstract}
To realize China's Intended Nationally Determined Contribution on Climate Change for post-2020 period, we should implement a plan for renewable energy development. How to choose a development order for different kinds of renewable energy, such as hydro power, solar power, and wind power? This paper simulates the electricity system with EnergyPLAN model. When we make an assumption that the demand of electricity in the year 2030 is 11800TWh per year, the required minimum capacity of total coal-fired electricity range from 1127GW to 1214GW.To lower the coal-fired capacity, more research should be done. Propose policy recommendations for renewable energy development. It shows that if more and more wind power is installed in RES-40 system, the analyzed results with the selected criteria will be better. It is a dynamic process to a more sustainable energy system. EEP will be an important problem when the share of RES reaches $50 \%$ or more in total electricity production.
\end{abstract}

Keywords- Renewable energy; EnergyPLAN; Energy transition; Renewable energy mix; Sustainability assessment

\section{INTRODUCTION}

Renewable energy development is a major response to address the issues of climate change and energy security [1]. Both developed and developing countries have committed to reduce their emissions through the increased use of renewable energy [2]. China formally submitted its Intended Nationally Determined Contribution (INDC) to the United Nations Framework Convention on Climate Change for post2020 period. In this climate activation, five objectives will be realized by 2030: (i) achieving the peaking of carbon emission at 2030 or earlier; (ii) increasing the share of nonfossil in primary energy consumption to account for at least $20 \%$; (iii) lowering carbon dioxide emissions per unit of GDP by $60 \%-65 \%$ from 2005 level around 2030; (iv) increasing its forest stock volume to a total of around 4.5 billion cubic meters compared to 2005 levels; (v) putting forward measures to limit or reduce GHG emission [3]. In order to realize the target, newly installed renewable electricity capacity should be $800-1000 \mathrm{GW}$ in the following
15 years. Total electricity capacity is $1329 \mathrm{GW}$ of which coal electricity accounts for a majority at present [4].

Compared with the former results, institutions increased their predicted share of non-fossil energy consumption in primary energy consumption after the INDC was submitted. MIT forecast that the percentage of non-fossil in primary energy consumption will be $14.4 \%$ in 2030 [5], and enhanced the share to the data to $24.3 \%$ in its newest report [6]. In IEA's "New Policies Scenario", there will be $21.1 \%$ of non-fossil resources in primary energy demand in 2030 [7], an increase of 6\% compared with its report in 2014 [8]. However, not all the institutions had a positive view on the development of renewable energy in China. Exxon Mobile did not have the data of 2030 , the percentage of non-fossil resources increased from $15 \%$ to $23 \%$ between 2025 and 2040 [9].

Despite a large number of literatures about renewable energy system, there are limited studies to create a renewable energy system due to the difficulties to storage, instabilities of RES and other practical issues. Hence, there are many questions remaining unsolved. Which kind of renewable energy is more reliable? How can we choose a more sustainable renewable energy system? What are the barriers for a more sustainable renewable energy system?

This paper investigates the options of renewable energy development in energy transition for the 2030 energy and emission target in China. Nuclear power, hydropower, solar photovoltaics, wind power is considered in this paper.

\section{METHODOLOGICAL APPROACH}

\section{A. EnergyPLAN}

The EnergyPLAN model is a deterministic, descriptive, and analytically programmed energy economic modeling platform used to simulate energy system with high degrees of renewable energy in regional or national scale [10]. Compared with other energy system model, energy system is simulated hour by hour due to the instability of renewable electricity production. The main line of this model is how the 
hourly electricity, heating and other demands are met. In this software, input data includes electricity, heating, cooling, and other demands, capacity of electricity and heating plants, capacity of renewable power and its distribution. To analysis the options of electricity, thermal power, and CHP power are treated as adjustment to meet the demand of electricity, so there is a minimum capacity of thermal and CHP power production to meet the gap between renewable electricity and electricity demand.

Both technical and economical optimization strategies are provided in the EnergyPLAN software to design an energy system. For technical optimization, the aim is minimizing fossil-fuel consumption without any cost inputs; for economical optimization is minimizing total operational expenses [10][11]. Detailed technical data, like start up/shut down costs are not included in the software. Though a competitive environment can be considered in the EnergyPLAN model[12], it cannot met the requirement of sustainability evaluation. So a strategy making analysismodel should be applied based on the results calculated from EenergyPLAN.

\section{B. Multi-criteria Analysis}

Multi-criteria methods are widely used to analysis sustainable energy management such as energy strategies making and electricity mix evaluating [13]. The methodology is suitable for objective examination of complex issues that have high uncertainty, different perspectives, various data forms and diverse stake holder opinions [14]. We applied multi-criteria to evaluate the sustainability of different electricity generation mix.

Our evaluation covers four different criteria, total costs, excess electricity, and jobs creation which are on behalf of economic, environmental ,technical and social impacts from RES respectively. The first three criteria can be calculated by Energyplan model and the rest are calculated with the method below.

\section{1) Total generation costs}

Total annual costs are sum of variable costs, fixed operation costs and annual investment costs accrued in the modelling year. We select the parameter presented in the EnergyPlan model of China, reference [15].

2) Total mix capacity

Minimum total mix capacity method was presented by [16] to identify the optimal renewable energy mix when the share of fossil electricity or nuclear are limited or there is a minimum share of renewable power in the electivity sector. In other words, total power mix capacity is also a criterion to measure an electricity system. In high RES, the installed capacity of fossil is used to ensure the stability of power supply due to the fluctuating nature of renewable sources. So the highest fossil power capacity required in a high RES scenario is the minimum capacity to meet the electricity demand. That is minimum total mix capacity seeks to identify the optimal combination of energy mix when a minimum production of RES is specified [17]. As it is expound in section 3.1, in technical strategy of EnergyPLAN model we can get the minimum fossil-fired capacity required to maintain the stable of power supply.

\section{3) Excess electricity}

The fluctuating characteristics of hydro, wind and solar $\mathrm{PV}$ power result in more electricity production than the actual demand as the increasing share of renewable energy electricity. The potential of pumped storage hydroelectricity as an electricity storage technology is of significant meaning except for its high investment costs. Minimization of excess energy is a crucial component of future systems based on RES [18], and the amount of electricity exceeding the existing demand is becoming a criteria to assess the high renewable electricity system. EnergyPLAN seeks to optimize the energy resources, giving priority to RES production and trying to reduce the utilization of storable energy whenever possible [17].

\section{4) Job creation}

In this section, we select job creation as a criteria stand for social sustainability due to it is one of the most worthy of attention in a transition to a more sustainable energy system. Job creation was calculated by different methods and for different regions. Employment factor method was used in a lot of literatures ([19] [20] [21]) to assess employment from power plants. The estimation of the job creation potential for the different scenarios is based on the method used by [22]( hydro, PV, wind and biomass) and [23](geothermal) . The total number of jobs is calculated as the sum of direct jobs related to maintain the capacity of power plants and indirect jobs related to the electricity production.

\section{HIGH RES SCENARIO}

\section{A. RES Share in Electricity System}

According to the former analysis, hydro power has its obvious advantages in both policy support and experiences. Hence, hydro power definitely plays an outstanding role in electricity production in mid-long term. In our assumption, almost all of the economically potential hydro power is developed by 2030 which is expected to reach $400 \mathrm{GW}$ at least and a maximum capacity of $650 \mathrm{GW}$.

In this paper, we use the electricity demand and growth rate in high scenario forecasted by [24]. Based on the economic analysis of different areas in China, LEAP, sector analysis and product forecast were used to assess the demand of electricity generation in mid-long term. The electricity demand will reach to $11800 \mathrm{TWh}$ by 2030 in his forecast.

Geothermal, biomass, nuclear and natural gas capacity is assumed to $30 \mathrm{GW}, 73 \mathrm{GW}$ (generation 324TWh), 150GW and $200 \mathrm{GW}$ respectively.

There is not a specific plan about how much is the share of renewable electricity in China's electricity mix, but the target is to achieve the $50 \%-60 \%$ maximum of coal-fired thermal and CHP power in total electricity supply by 2030 . We model the high RES scenario with the method in Section 3 and with the renewable potential as a limit in Section 2.

\section{B. $40 \%$ RES Electricity System}

In this section, a $40 \%$ RES electricity system is chosen to assess the sustainability of different renewable energy mix for electricity production. Hydro capacity remains the same with scenarios in section 4.1, namely low hydro wit capacity 
of $400 \mathrm{GW}$ and $500 \mathrm{GW}$ for mid hydro and $650 \mathrm{GW}$ for high hydro. In the three scenarios, there are nine sub-scenarios with solar PV capacity from $100 \mathrm{GW}$ to $800 \mathrm{GW}$. Wind power capacities are changed to insure that the total electricity supply a share of $40 \%$ in electricity system.

\section{RESULTS}

This section present the results of the analyses conducted on the three high RES scenarios. Section 5.1 shows the electricity for several combinations of wind and PV power. Section IV B presents the minimum coal fired thermal and CHP capacity related to every wind-PV combination. Section $\mathrm{C}$ shows the costs of total generation and the excess electricity of $40 \%$ renewable electricity in electricity production of the three scenarios. Section IV D compares the sustainability using the method presented in section III.B.

\section{A. Annual RES Electricity Production Share}

Fig1-3 show the share of RES with increase in both the $\mathrm{PV}$ and wind power capacity using the hourly PV and wind power production in the ref [15]. As we can see, there are different kinds of renewable energy mix to decrease the share of coal-fired thermal or CHP electricity production to a maximum of $50 \%-60 \%$.

Duo to different fluctuating characteristics, hydro power produces more electricity than wind power and wind power produce more than PV power for equal capacity. However, if RES renewable contained hydro power only, it was impossible to meet the maximum share of coal-fired electricity.

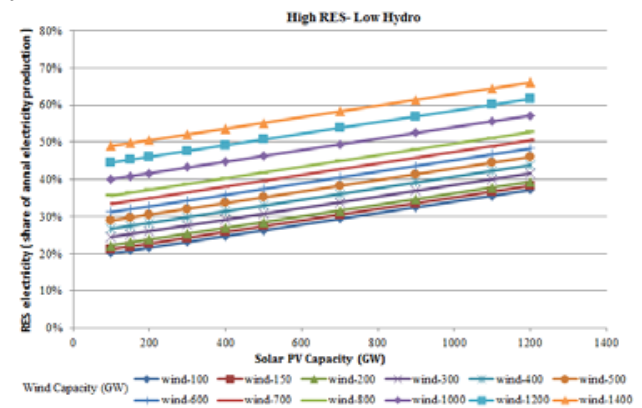

Figure 1. High RES-Low Hydro scenario: share of RES electricity production.

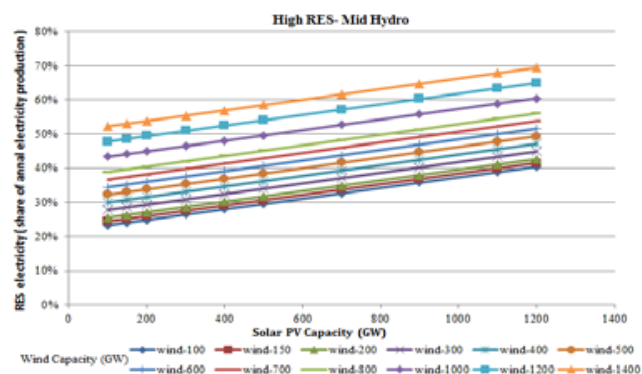

Figure 2. High RES-Mid Hydro scenario: share of RES electricity production.

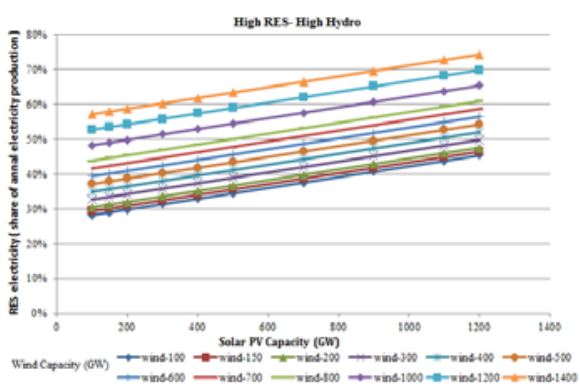

Figure 3. High RES-High Hydro scenario: share of RES electricity production.

\section{B. Can Higher RES Lower the Necessary Coal-fired Power Capacity?}

Fig 4-6 show the necessary coal-fired power capacity with renewable energy mix scenarios. To ensure electricity supply and avoid electricity import, a minimum thermal capacity is required. Higher RES can lower the necessary coal-fired power capacity in the three High RES scenarios, but the impact is weak. In the selected scenarios, the necessary coal-fired power capacity ranges from $1114 \mathrm{GW}$ to $1241 \mathrm{GW}$. Hydro power makes higher contributions than that from wind and PV power. The results do not change when the PV capacity increase in Higher RES-Low Hydro scenario. When the capacity of PV is lower than 200 GW (Higher RES-Mid Hydro scenario) and 300 GW (Higher RES-High Hydro scenario), it shows a decrease trend for the necessary coal-fired power capacity.

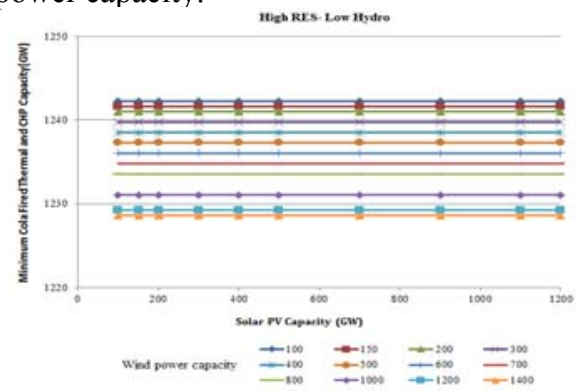

Figure 4. High RES-Low Hydro scenario: minimum necessary coal-fired electricity capacity.

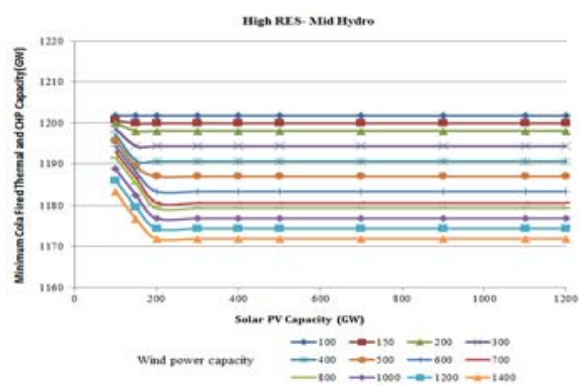

Figure 5. High RES-Mid Hydro scenario: minimum necessary coal-fired electricity capacity. 


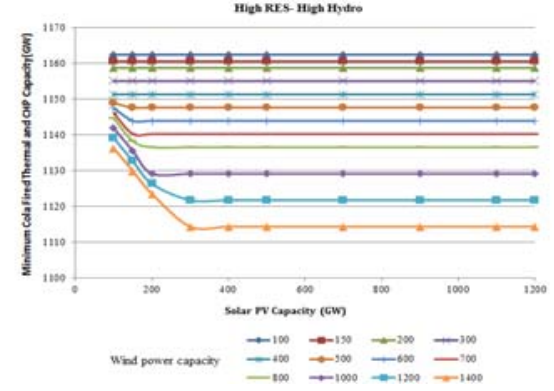

Figure 6. High RES-High Hydro scenario: minimum necessary coal-fired electricity capacity.

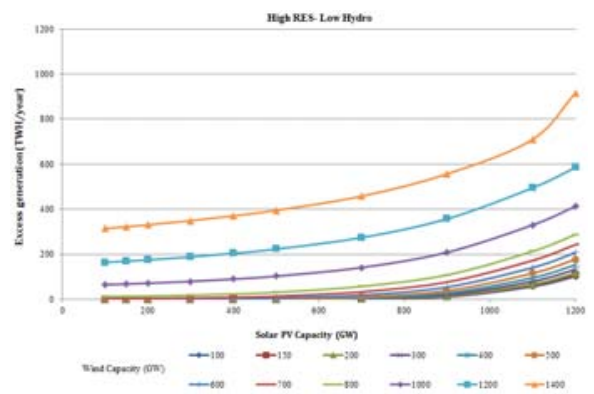

Figure 7. Excess electricity production in High RES-Low Hydro scenarios.

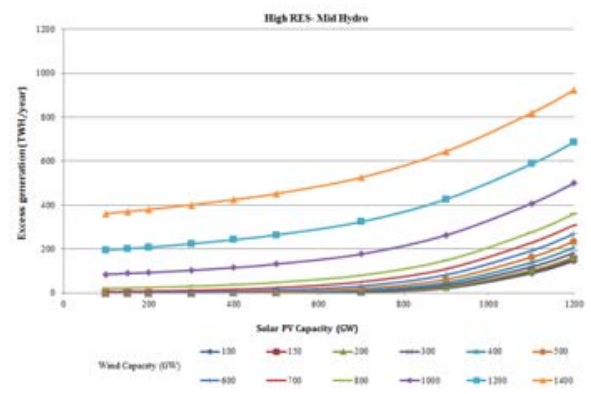

Figure 8. Excess electricity production in High RES-Mid Hydro scenarios.

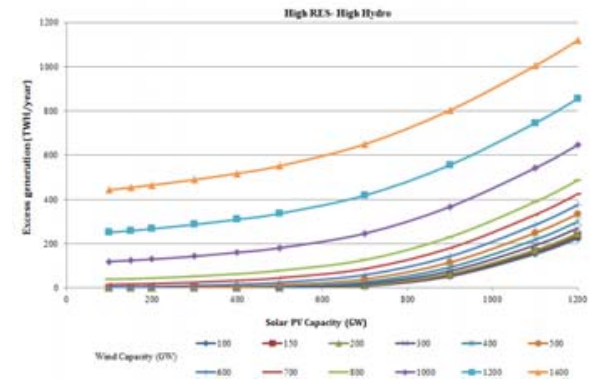

Figure 9. Excess electricity production in High RES-High Hydro scenarios.

Excess electricity production represents a serious problem for a system and must be avoid or the problem could face overcharging problems [16]. The higher RES share of electricity production, the higher EEP. It is noteworthy that the growth rate of EEP is increasing as more solar PV power is installed. In the highest RES scenarios, EEP is high than $1000 \mathrm{GW}$, nearly $10 \%$ of total electricity demand. On the other hand, combinations of wind and PV power can lower the excess electricity production effectively especially in a higher RES electricity system.

\section{Excess Electricity and Total Costs Analysis of A 40\% RES}

Fig 10 shows the excess electricity trend as the capacity of PV power increase for a $40 \%$ RES in three hydro power scenarios. In the three scenarios, the higher PV capacity value, the lower the corresponding wind power production. In each scenario, there is a peak for excess electricity production and the peak will be at a lower PV power capacity as the hydro power capacity increase. The PV capacity of which the excess electricity will be valley at $300 \mathrm{GW}, 400 \mathrm{GW}$ and $500 \mathrm{GW}$ for the three scenarios. Higher hydro capacity scenario has lower excess power production for equal solar PV capacity.

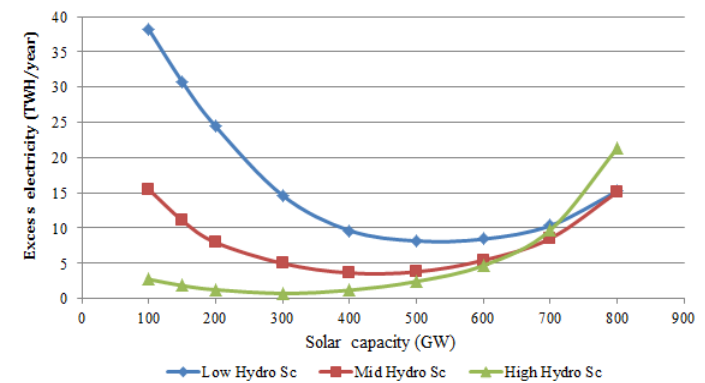

Figure 10. Excess electricity production in all three High RES scenarios

Fig 11 shows the total cost for each scenario including variable costs, fixed operation cost and annual investment costs. The variable costs and fixed costs do not change in the same hydro power scenario. The annual investment increase as the more PV capacity is installed. Total costs decline steadily with the increasing hydro power capacity. In the high hydro power scenario, there is a least total cost at nearly 2900 billion RMB, 400 billion RMB less than the highest costs in low hydro scenario.

\section{Sustainability Analysis for A 40\% RES in Electricity Production}

We analysis the sustainability of the 40\% RES with four criteria: the total minimum necessary costs, the total minimum necessary capacity, the excess electricity and direct jobs.CO2, land use and water print are also very important criteria for sustainability analysis, but once the share of renewable electricity is fix, there is almost not differences among the scenarios due to the resource mix. A method is used to make the criteria being dimensionless to analysis the sustainability in different scenarios as show in Fig 12-14. It is a quantitative method to evaluate the merits of each renewable energy mix. 

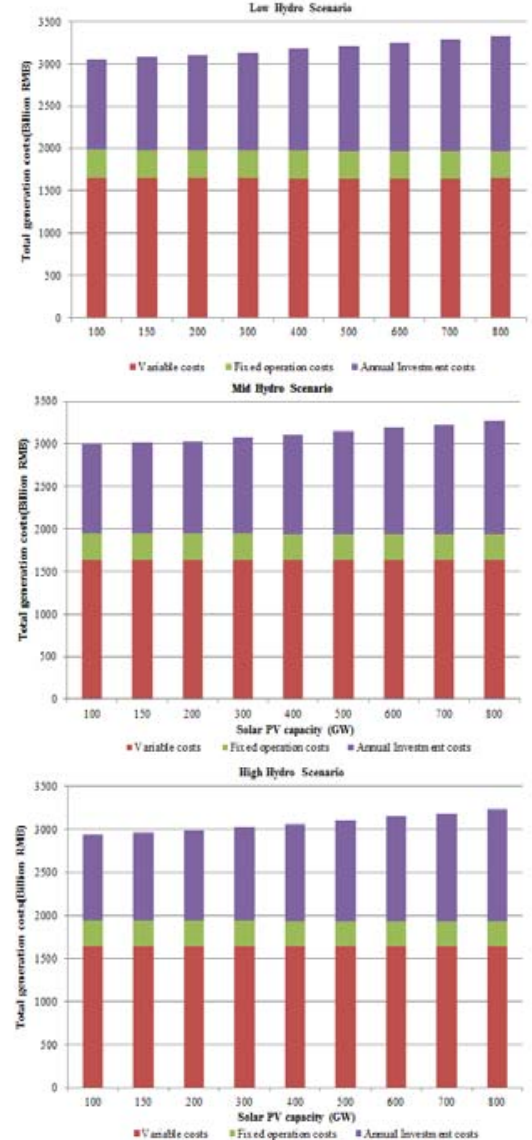

Figure 11. The total costs required in the three High RES scenarios in the year 2030 .

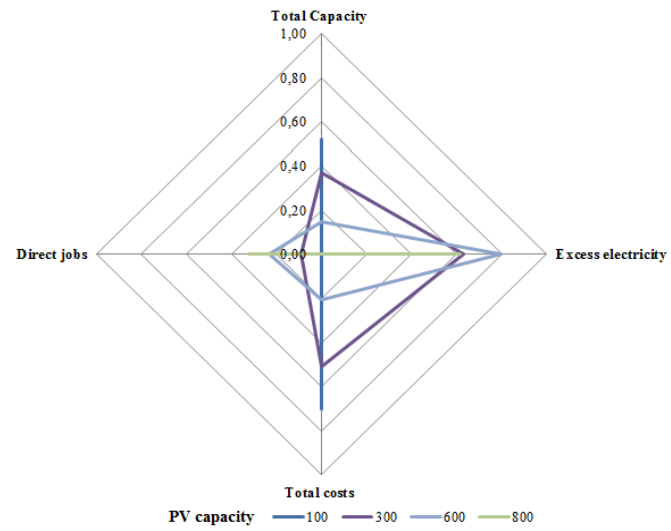

Figure 12. Sustainability of High RES- Low Hydro scenario with selected PV capacity $(100 \mathrm{GW}, 300 \mathrm{GW}, 600 \mathrm{GW}$ and $800 \mathrm{GW})$. Bigger value means a better impact.

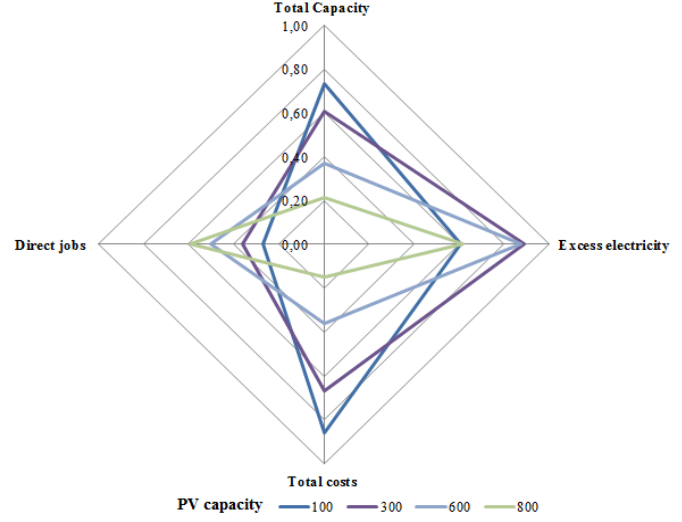

Figure 13. Sustainability of High RES- Mid Hydro scenario with selected PV capacity (100GW, 300GW, 600GW and 800GW). Bigger value means a better impact.

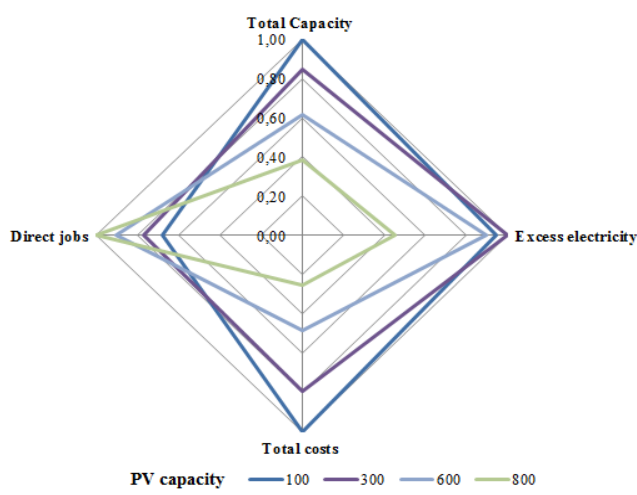

Figure 14. Sustainability of High RES- High Hydro scenario with selected PV capacity (100GW, 300GW, 600GW and 800GW). Bigger value means a better impact.

As shown in Fig 12-14, bigger value means better impacts for electricity system in each dimension. High hydro RES show the best results in the three scenarios in all dimensions. The $800 \mathrm{GW}$ PV power capacity can create more jobs than other scenarios but has highest total capacity, excess electricity and costs, so it is not sustainable. Duo to the resource limit even highest hydro power capacity cannot meet the demand of $40 \%$. It is the most affordable that more electricity from wind than from PV should be produced. Solar power could be a way to lower the excess electricity.

\section{CONCLUSIONS}

In this study, we introduced a methodology including EnergyPLAN model and multi--criteria analysis to identify an optional renewable energy mix for the energy transition in China China's energy sector. To lower the share of coal-fired power production to a maximum of $50 \%-60 \%$, a RES- 40 system in which renewable energy source account for $40 \%$ of total primary energy supply is established to analysis the optional renewable energy mix. For this analysis, we conducted three scenarios and lots of sub-scenarios according to current energy policy. In all the scenarios, nuclear, geothermal, biomass, natural gas plants remain the 
same as planned in industry reports. Hydro power by itself cannot meet the demand of RES-40 system. So installed hydro power capacity were added with three levels, creating High RES-Low hydro (400GW), High RES-Mid hydro $(500 \mathrm{GW})$ and High RES-high hydro $(650 \mathrm{GW})$ scenarios. Increasing amounts of wind and PV power were analyzed to identify combination of hydro, wind and PV resulting in a minimum of $40 \%$ RES electricity by 2030 in the three scenarios to make the system self-sufficient, i.e., independent from electricity imports, was also calculated. Based on the conducted scenarios, we analyzed the 40-RES system with three mail evaluation criteria (economic, energy security, and social) to assess the sustainability of the system.

The major findings in this study are as follows:

Even though we can achieve the target to lower the maximum share of coal-fired capacity to $50 \%-60 \%$ by numerous combination of hydro, wind and PV electricity capacity, it is hard to reduce the required minimum capacity of total thermal and CHP plants. When we make an assumption that the demand of electricity in the year 2030 is $11800 \mathrm{TWh}$ per year, the required minimum capacity of total coal-fired electricity range from $1127 \mathrm{GW}$ to $1214 \mathrm{GW}$.To lower the coal-fired capacity, more research should be done.

In each High RES scenarios, several wind and PV combinations achieve the target, but hydro itself is impossible for this object. The High RES -High Hydro shows the best evaluation results in all the three scenarios meaning that hydro power will play the most important role by 2030. In High RES -High Hydro scenario, EEP differences is small that we draw a conclusion that the subscenario: the capacity of solar PV power is $100 \mathrm{GW}$; wind, $551 \mathrm{GW}$ and hydro power capacity of $650 \mathrm{GW}$ is the best optional renewable energy mix for China's energy transition.

It is hard to realize the high hydro power scenarios with installed hydro power of $650 \mathrm{GW}$. In High RES- Low Hydro and High RES- Mid Hydro scenarios, the capacity of PV at $300 \mathrm{GW}$ shows the best evaluation results.

\section{REFERENCES}

[1] Wang B, Ke R Y, Yuan X C, et al. China' s regional assessment of renewable energy vulnerability to climate change[J]. Renewable and Sustainable Energy Reviews, 2014, 40: 185-195.

[2] Hua Y, Oliphant M, Hu E J. Development of renewable energy in Australia and China: A comparison of policies and status[J]. Renewable Energy, 2016, 85: 1044-1051.

[3] NDRC. Enhanced Actions on Climate Change: China's Intended Nationally Determined Contributions. National Development \& Reform Commissions of China, June.2015.

[4] Jenny Chu. RE 100- China briefing report, in Chinese. The Climate Group, 2015. http://www.theclimategroup.org/ assets/files/RE100China-briefing-report-Chinese-130415.pdf

[5] MIT. 2014 Energy and Climate Outlook. MIT's Joint Program on the Science and Policy of Global Change, October 2014.

[6] MIT. 2015 Energy and Climate Outlook. MIT's Joint Program on the Science and Policy of Global Change, October 2015.

[7] IEA. World Energy Outlook 2014. International Energy Agency, 2014.

[8] IEA. World Energy Outlook 2015. International Energy Agency, 2015.

[9] Exxon Mobile. The outlook for energy: A view to 2040. Exxon Mobile, 2015.
[10] Mahbub M S, Cozzini M, Østergaard P A, et al. Combining multiobjective evolutionary algorithms and descriptive analytical modelling in energy scenario design. Applied Energy, 2016, 164: 140-151.

[11] Cho S, Kim J. Feasibility and impact analysis of a renewable energy source (RES)-based energy system in Korea. Energy, 2015, 85: 317 328.

[12] Bjelić I B, Rajaković N. Simulation-based optimization of sustainable national energy systems. Energy, 2015, 91: 1087-1098.

[13] Pohekar S D, Ramachandran M. Application of multi-criteria decision making to sustainable energy planning - a review. Renewable and sustainable energy reviews, 2004, 8(4): 365-381.

[14] Hong S, Bradshaw C J A, Brook B W. Evaluating options for sustainable energy mixes in South Korea using scenario analysis. Energy, 2013, 52: 237-244.

[15] Xiong W, Wang Y, Mathiesen B V, et al. Heat roadmap China: New heat strategy to reduce energy consumption towards 2030. Energy, 2015, 81: 274-285.

[16] Vidal-Amaro, J.; Østergaard, P.; Sheinbaum-Pardo, C. Optimal Energy Mix For Transitioning From Fossil Fuels To Renewable Energy Sources - The Case Of The Mexican Electricity System. Applied Energy 2015, 150, 80-96.

[17] Vidal-Amaro J J, Østergaard P A, Sheinbaum-Pardo C. Optimal energy mix for transitioning from fossil fuels to renewable energy sources-The case of the Mexican electricity system. Applied Energy, 2015, 150: 80-96.

[18] Tafarte P, Das S, Eichhorn M, et al. Small adaptations, big impacts: Options for an optimized mix of variable renewable energy sources. Energy, 2014, 72: 80-92.

[19] Klein S J W, Whalley S. Comparing the sustainability of US electricity options through multi-criteria decision analysis. Energy Policy, 2015, 79: 127-149.

[20] Brand B, Missaoui R. Multi-criteria analysis of electricity generation mix scenarios in Tunisia. Renewable and Sustainable Energy Reviews, 2014, 39: 251-261.

[21] Maxim A. Sustainability assessment of electricity generation technologies using weighted multi-criteria decision analysis. Energy Policy, 2014, 65: 284-297.

[22] Cai W, Wang C, Chen J, et al. Green economy and green jobs: Myth or reality? The case of China's power generation sector. Energy, 2011, 36(10): 5994-6003.

[23] Rutovitz J, Usher J. Methodology for calculating energy sector jobs. Institute for Sustainable Futures, 2010.

[24] Shan et al. Research on electricity demand of China during the 13th five-year plan and med-term-\&long term periods. Electric Power, 2015, 48(1):6-14. In Chinese. 